\section{Literature Cited}

1) Calderbank, P. H. and M. B. Moo-Young: Chem. Eng. Sci., 16, 39 (1961).

2) Linke, W. F.: "Solubilities", American Chemical Society, Washington D.C. (1965).

3) Misic, D. M. and J. M. Smith: Ind Eng. Chem., Fundam., 10, 380 (1971).

4) Niiyama, H., and J. M. Smith: AIChE J., 22, 961 (1976).

5) Satterfield, C. N.: "Mass Transfer in Heterogeneous
Catalysis", p. 108, p. 127, MIT Press, Cambridge, Mass. (1970).

6) Sherwood, T. K. and E. J. Farkas: Chem. Eng. Sci., 21, 573 (1966).

7) Valentin, F. H. H.: "Absorption in Gas-Liquid Dispersion”, E. and F. N. Spon Ltd., London, England (1976).

(Presented at the 11th Autumn Meeting of The Soc. of Chem. Engrs., Japan, at Tokyo, October 5, 1977).

\title{
APPLICATION OF PARTICLE ENLARGEMENT BY CONDENSATION TO INDUSTRIAL DUST COLLECTION
}

\author{
Tetsuo YOSHIDA, Yasuo KOUSAKA, KikUo OKUYAMA \\ AND FUMINORI NOMURA \\ Department of Chemical Engineering, University of \\ Osaka Prefecture, Sakai 591
}

\begin{abstract}
Application of the phenomena of particle growth by condensation to industrial dust collection was studied. The analysis to evaluate the extent of size enlargement was first introduced to the two essential and industrially useful methods, one of which is the mixing of hot saturated air with cold air, the other being injection of steam into air. Four typical processes are proposed for effective application to industrial exhaust gas and the procedure of using these processes is illustrated according to the various conditions of exhaust gas. The technique for size enlargement of aerosol particles by condensation was found to be essentially applicable to any industrial exhaust gas which contains submicron dust particles in low number concentration when the appropriate process shown herein is selected.
\end{abstract}

\section{Introduction}

Fundamental analysis and experimental studies of the growth of aerosol particles by condensation were discussed in our previous paper ${ }^{2}$, where it was suggested that particle growth by condensation is one of the most promising preconditioning techniques for the collection of submicron dust particles. Industrial application of the fundamental results is developed in this paper.

Condensation of water vapor on aerosol particles not consisting of soluble substances will essentially occur wherever a certain degree of supersaturation is produced around the particles. The fundamental analysis of the method of producing supersaturation by mixing hot saturated air with cold air, which was reported already ${ }^{2)}$, is first briefly cited, and then that

Received January $5, \overline{1978 .}$. Correspondence concerning this article should be addressed to Y. Kousaka. T. Yoshida is now at Dept. of Mech. Eng., Chubu Inst. of Tech., Kasugai 487 and F. Nomura is now with Kanebo Co., Ltd., Osaka 534. of the additional method of injecting steam into air is proposed. The establishment of economical processes to produce supersaturation using these methods will be important from the industrial point of view. Processes for this purpose are discussed and developed under consideration of various conditions, such as temperature and humidity, of industrial exhaust gas. Some processes are proposed according to various conditions of exhaust gas and are arranged into charts for facility of design of a preconditioner of industrial dust collection. The applicability of particle growth by condensation to dust collection was studied experimentally by observing the actual increase in particle size by condensation and the improvement of dust collection efficiency of the wet scrubber.

\section{Basic Considerations}

In this section the fundamental aspects of particle growth by condensation will be briefly introduced.

The point " $i$ " on the humidity chart of Fig. 1 indi- 


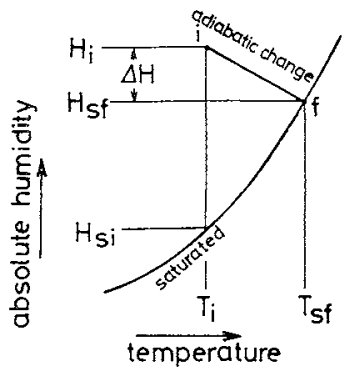

Fig. 1 Change in humidity and temperature due to condensation
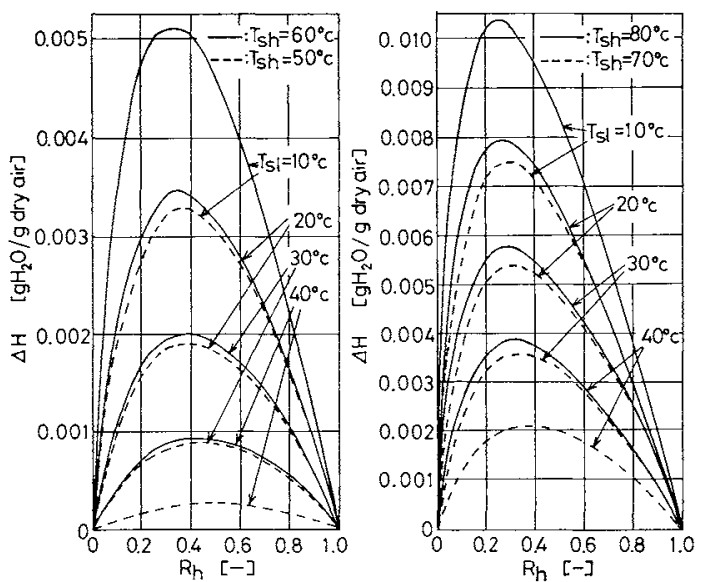

Fig. 2 Condensable water vapor $\Delta H$ at various mixing conditions

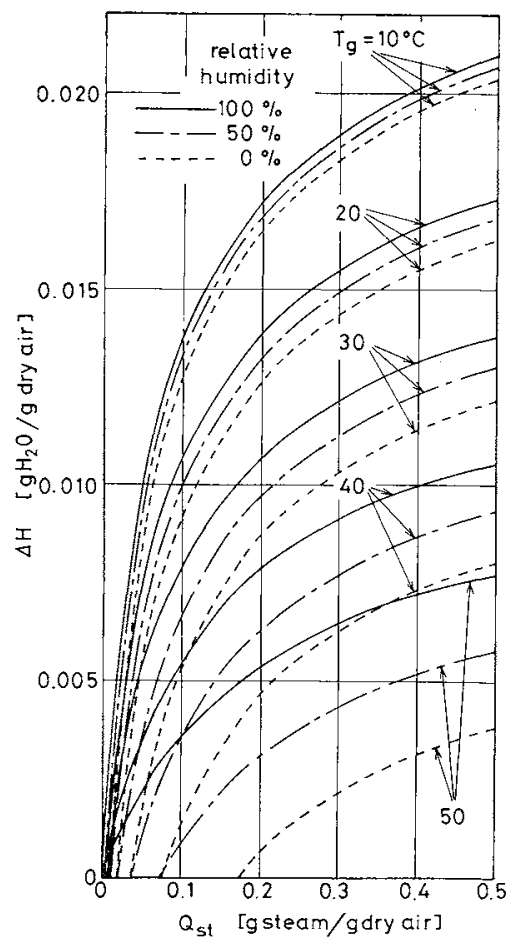

Fig. 3 Condensable water vapor $\Delta H$ against quantity of steam injection $Q_{s t}$

cates a state of supersaturation of air. The value of $\Delta H$ shown in the figure represents the quantity of condensable water vapor per unit mass of dry $\mathrm{air}^{2}$. To attain point " $\mathrm{i}$ ", two methods can be considered to be effective: that of mixing high-temperature saturated air with colder air and that of stream injection into air. The values of $\Delta H$ can be given by the following enthalpy and material balances on dry air basis:

(mixing method) ${ }^{2}$

$$
\begin{aligned}
& R_{h} i_{s h}+\left(1-R_{h}\right) i_{s l}=i_{s f}+\Delta H i_{w f}^{\prime} \\
& R_{h} H_{s h}+\left(1-R_{h}\right) H_{s l}=H_{s f}+\Delta H
\end{aligned}
$$

(steam injection method)

$$
\begin{gathered}
i_{g}+Q_{s t}\left\{x i_{s t}^{\prime \prime}+(1-x) i_{s t}^{\prime}\right\}=i_{s f}+Q_{s t}(1-x) i_{w f}^{\prime}+\Delta H i_{w f}^{\prime} \\
H_{g}+Q_{s t} x=H_{s f}+\Delta H
\end{gathered}
$$

Some of the calculated results for $\Delta H$ are shown in Figs. 2 and 3.

When all of the vapor corresponding to the amount of $\Delta H$ are assumed to condense upon particles suspended in the supersaturated atmosphere, the increase in size of particles undergoing condensation can be evaluated by the following equation ${ }^{2)}$.

$$
D_{v f} \fallingdotseq\left(6 \Delta H / \pi n_{0}\right)^{1 / 3} \text { when } D_{v f}^{3} \gg D_{v i}^{3} \text { and } \rho_{s} \fallingdotseq 1
$$

$n_{0}$ represents the particle number concentration of aerosol on dry air mass basis. $D_{v i}$ and $D_{v f}$ represent the volume mean diameters of the particles before and after growth, respectively.

The growth rate of particles undergoing condensation was found to be very rapid in the previous work ${ }^{2}$, so the above analysis in equilibrium state only will be essential in developing this technique to industrial application.

\section{Typical Operations to Obtain High Temperature and Low Temperature Saturated Air}

\section{1 High-temperature saturated air}

a) Adiabatic humidification When exhaust gas is at high temperature or moderate temperature with high humidity, direct contact of the gas with recirculating water in a humidifier will be effective. This operation is simple and no heat source is necessary. The operation is illustrated as line (a) in the humidity chart of Fig. 4.

b) Humidification by contacting with heated water When the exhaust gas is at moderate temperature and humidity, contact with heated water will be effective. The line (b) in Fig. 4 illustrates this operation. c) Humidification by steam injection This operation will be essentially effective for gas of any temperature or humidity, but this is especially effective for low-temperature gas, the reason for which appears later. The line (c) in Fig. 4 illustrates this operation.

\section{2 Low-temperature saturated air}

d) Adiabatic humidification When the exhaust gas is at low temperature or low humidity, the same 


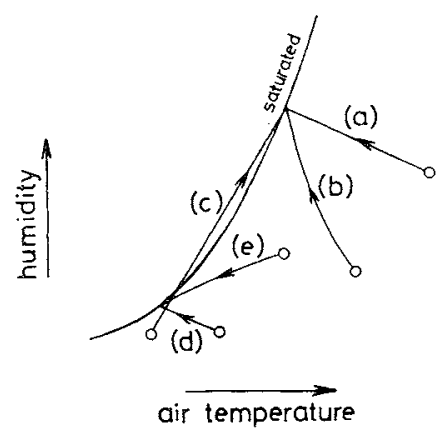

Fig. 4 Typical operations to obtain high- and low-temperature saturated gases

method as (a) is applicable. This is shown as the line (d) in Fig. 4.

e) Dehumidification by contacting with cooling water When the operation (d) is not usable, direct contact of gas with cooling water will be inevitable. This is shown as the line (e) in Fig. 4.

These typical operations are applied to industrial exhaust gas according to temperature and humidity of the gas in the following section.

\section{Methods to Produce $\Delta H$ in Various Industrial Exhaust Gas}

Some of the representative industrial processes to produce $\Delta H$ are discussed according to some typical gas conditions in this section. The property of exhaust gas was regarded as the same as that of air in the following discussion. The notations (a)-(e) in the following figures indicate the above classification for typical operations.

\section{1 High-temperature and high-humidity exhaust gas}

This is probably the most advantageous case for applying the method of particle growth by condensation when cooling water is obtainable. The flow sheet of this process is shown in Fig. 5. Gas after adiabatic humidifier is divided into two parts. One part is dehumidified by contacting with cooling water, and is then mixed with the other to produce $\Delta H$ or to enlarge the particles in gas at the mixing chamber. This process is named " $\mathrm{A}$ ". The value of $\Delta H$ depends on the temperature $T_{g}$ and humidity $H_{g}$ of exhaust gas, and on the temperature of the cooling water available. The correlation among them was calculated by Eqs. (1) and (2), and is illustrated on the right upper side of the humidity chart of Figs. 6 and 7. The mixing ratio $R_{h}$ was chosen in any case as the optimal calculated values shown in Fig. 2. If one may require the value of $\Delta H=0.006$ and if a cooling water temperature of $20^{\circ} \mathrm{C}$ is available, then the exhaust gas conditions must exist at least on the line of $20^{\circ} \mathrm{C}$ cooling water in Fig. 7; for instance $T_{g}=1000^{\circ} \mathrm{C}$ and $H_{g}=0.07 \mathrm{~g} \mathrm{H}_{2} \mathrm{O} / \mathrm{g}$ dry air, $T_{g}=100^{\circ} \mathrm{C}$ and $H_{g}=$ $0.32 \mathrm{~g} \mathrm{H}_{2} \mathrm{O} / \mathrm{g}$ dry air and so forth. The temperature
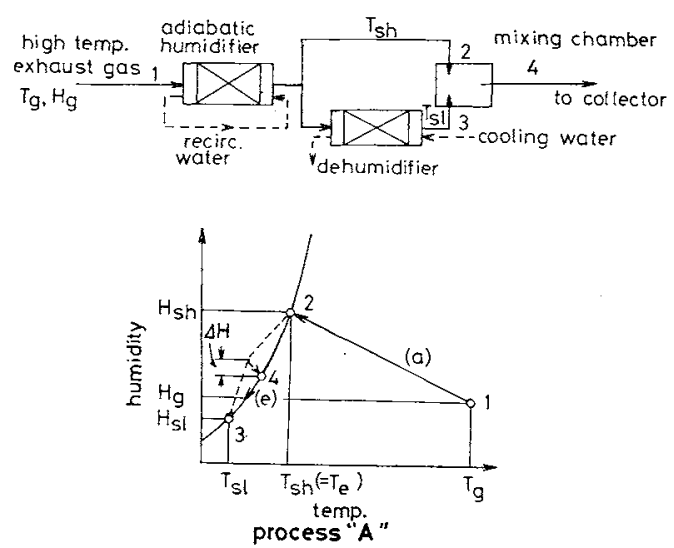

Fig. 5 Illustration of process " $A$ "

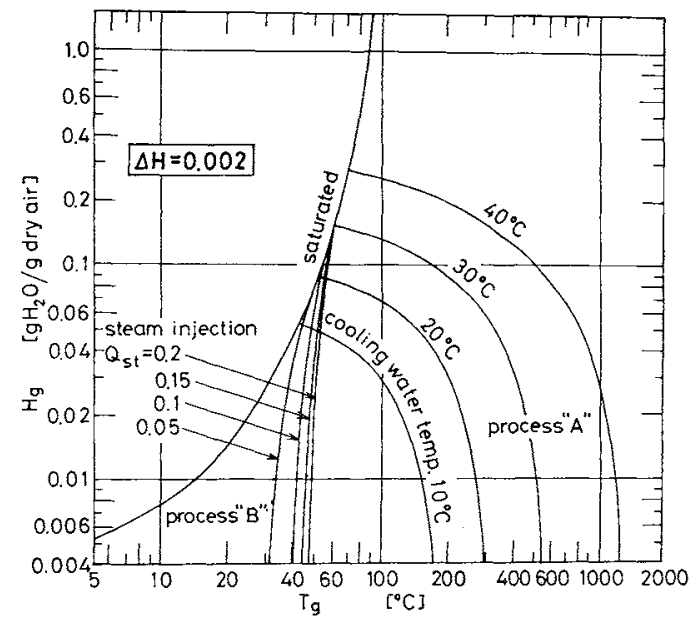

Fig. 6 Application of processes "A" and "B" to various exhaust gas conditions ( $\Delta H=0.002$ )

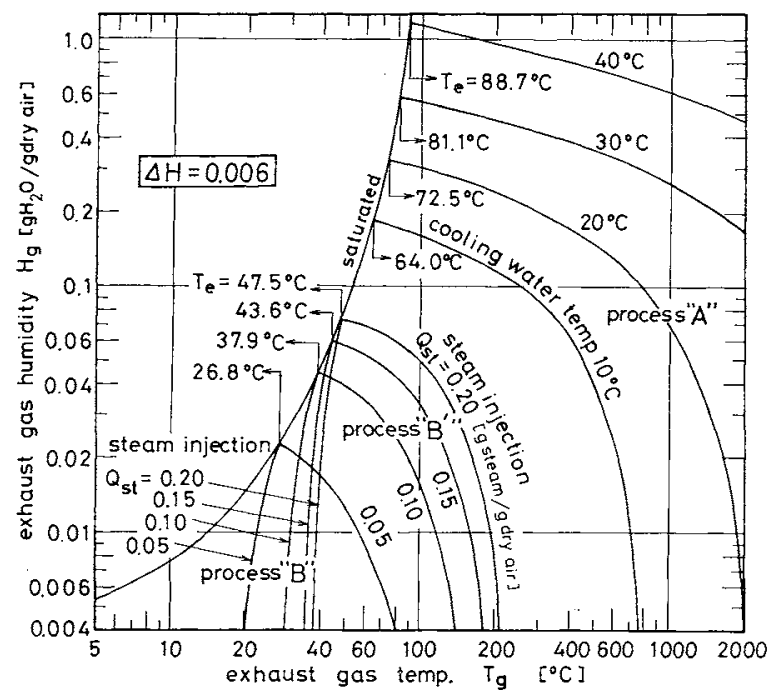

Fig. 7 Application of processes " $A$ ", " $B$ " and "B" to various exhaust gas conditions $(\Delta H=$ 0.006)

of saturated air or the equilibrium temperature after adiabatic humidification, in this case, comes to $T_{e}=$ $72.5^{\circ} \mathrm{C}$. It is a matter of course that larger values 

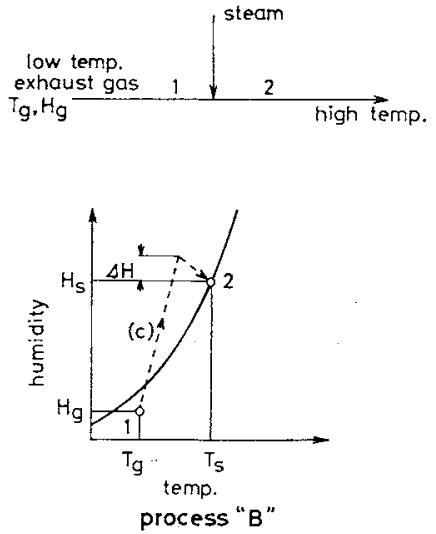

Fig. 8 Illustration of process "B".
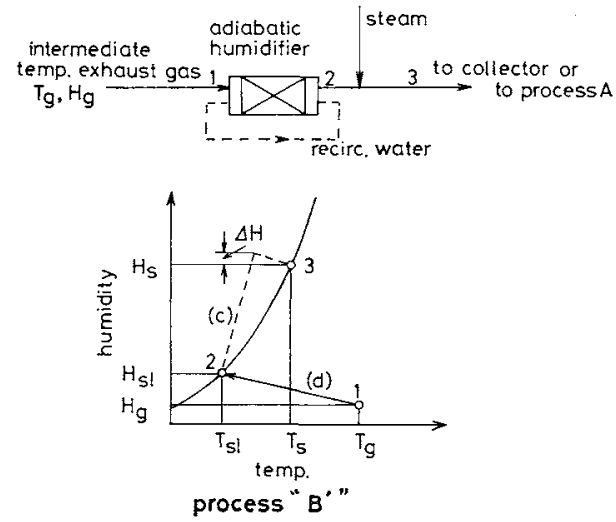

Fig. 9 Illustration of process " $B$ "'

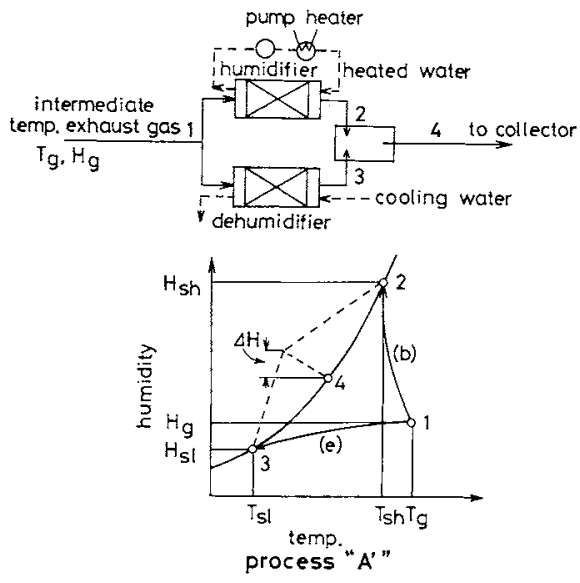

Fig. 10 Illustration of process " $\mathrm{A}$ "

than $\Delta H=0.006$ can be obtained if the gas conditions are on the upper side of the line of $20^{\circ} \mathrm{C}$ cooling water in Fig. 7.

\section{2 Low-temperature exhaust gas}

In this case steam injection method is effective, but has the fault that it requires saturated steam as a heat and water-vapor source. This process is very simple, as shown in Fig. 8, and is named " $B$ ". The value of $\Delta H$ depends on the steam quantity $Q_{s t}$ and on exhaust gas conditions such as $T_{g}$ and $H_{g}$. The correlation among them was calculated by Eqs. (3) and (4) and is illustrated on the left side of the humidity chart of Figs. 6 and 7. As the property of steam, $100^{\circ} \mathrm{C}, 1 \mathrm{~atm}$ and unity in dryness fraction were assumed in the calculation. If the same value of $\Delta H$ as in the above example is required and if the steam quantity of $Q_{s t}=0.1 \mathrm{~g}$ steam $/ \mathrm{g}$ dry air is available, then the exhaust gas conditions must exist at least on the line of $Q_{s t}=0.1$ in Fig. 7. Larger values than $\Delta H=0.006$ can be obtained if the gas conditions are on the left side of this line. The temperature rise in air is also illustrated in the figure as $T_{e}$, in this example $T_{e}=37.9^{\circ} \mathrm{C}$. If the saturated air after steam injection is at high temperature, the process " $\mathrm{A}$ " may be applied successively after steam injection. This is one of the advantage of this process.

\section{3 Gas having intermediate conditions}

When exhaust gas is at a temperature below about $200^{\circ} \mathrm{C}$ and low humidity, steam injection can be applied after application of adiabatic humidification. This process is shown in Fig. 9, and is named process " $B$ "' because of its similarity to process " $B$ ". The calculated results in this case are illustrated in the humidity chart of Fig. 7.

When both hot water and cooling water are available, the following process may be applicable. One part of the exhaust gas is humidified by hot water to obtain high-temperature saturated air, and the remainder is cooled by contacting with cooling water to obtain low-temperature saturated air. Then they are mixed to produce $\Delta H$. The process is shown in Fig. 10, and is named process " $\mathrm{A}$ ". The calculated results cannot be shown in this case in Figs. 6 and 7 because the additional parameter of heated water temperature is necessary. The value of $\Delta H$, however, is obtainable for every given condition since the temperature of points " 2 " and " 3 " in Fig. 10 can be evaluated from given gas conditions.

\section{Utilization of the Above Results}

The steps of procedure to utilize the above results for industrial purposes are as follows. The appropriate process is first selected according to the given temperature and humidity of exhaust gas, referring to Figs. 6 and 7. The value of $\Delta H$ is next evaluated from calculation by setting up the quantity of steam or the temperature of cooling water which is obtainable. Then the volume mean diameter of grown particles, $D_{v f}$, can be evaluated from Eq. (5), using the value of $\Delta H$ and knowing the particle number concentration of the gas, $n_{0}$. A dust collector after the preconditioned gas should be designed using the value $D_{v f}$ thus obtained. If the value $D_{v f}$, on the other hand, is first given from the point of performance of an installed collector, the value $\Delta H$ should be first 
determined from Eq. (5) knowing the value $n_{0}$. Consequently the steam quantity $Q_{s t}$ or cooling water temperature will be determined from the figure or calculated using the known value of $\Delta H$ and knowing the gas conditions.

(example)

$T_{g}=30^{\circ} \mathrm{C}, H_{g}=0.01 \mathrm{~g} \mathrm{H}_{2} \mathrm{O} / \mathrm{g}$ dry air and $n_{0}=10^{8}$ particles/g dry air (roughly corresponds to $10^{5}$ particles $/ \mathrm{cm}^{3}$ gas) are given. It is required to enlarge submicron particles in the gas to 5 microns in $D_{v f}$.

In this case the required value of $\Delta H$ is found to be $0.006 \mathrm{~g} \mathrm{H}_{2} \mathrm{O} / \mathrm{g}$ dry air from Eq. (5). The appropriate process in this case is found to be process " $\mathrm{B}$ " because of low-temperature gas. The required stream quantity $Q_{s t}\left(100^{\circ} \mathrm{C}, 1 \mathrm{~atm} x=1\right)$ is then found to be $0.1 \mathrm{~g}$ steam $/ \mathrm{g}$ dry air from the point of $T_{g}=30^{\circ} \mathrm{C}$ and $H_{g}=0.01$ in Fig. 7 .

\section{Experimental}

Two kinds of experiments are shown in this section in order to examine the applicability of the particle enlargement method by condensation to industrial dust collection. The first experiment is to find the increase in particle size by the processes described above, and the second is to find the increase in collection efficiency of a scrubber when the preconditioning process is applied. These kinds of experiments are very difficult because of the difficulty in accurate measurement of the size of droplets suspended in hot gas.

In the first experiment, the experimental results for the process " $\mathrm{A}$ " "were reported in the previous paper", and so the results for the other processes will be shown in this section. Figure 11(a) shows the schematic diagram of the experimental method. This apparatus can be operated under processes " $A$ ", " $B$ " and " $B$ ", by opening and closing valves. The mixture of air with the combustion gas from gas burner was supplied as a high-temperature gas from the bottom of the adiabatic humidifier. The temperature of the gas was several hundred degrees Celsius for the process "A", about $200^{\circ} \mathrm{C}$ for the process " $\mathrm{B}$ " " and less than about $50^{\circ} \mathrm{C}$ for the process "B". Tobacco smoke ( $D_{v i}=0.85$ micron) and dust particles contained in combustion gas ( $D_{v i} \leq 0.1$ micron) were used as submicron dust particles. Total gas flow rate was 180 $l / \mathrm{min}$. In the experiment of the process " $\mathrm{A}$ ", the valves of $v_{1}$ and $v_{2}$ are adequately opened to obtain a certain mixing ratio $R_{h}$ keeping $v_{3}$ close. In the experiments of processes " $B$ " and " $B$ ", the valve of $v_{2}$ is closed and $v_{3}$ is moderately opened to inject a certain amount of steam into the gas. The steam condition was $100^{\circ} \mathrm{C}$ in temperature, $1 \mathrm{~atm}$. abs. in pressure and 1.0 in dryness fraction, and the quantity of steam injection ranged from 0.05 to $0.5 \mathrm{~g}$ steam $/ \mathrm{g}$ dry air. The technique of size measurement of

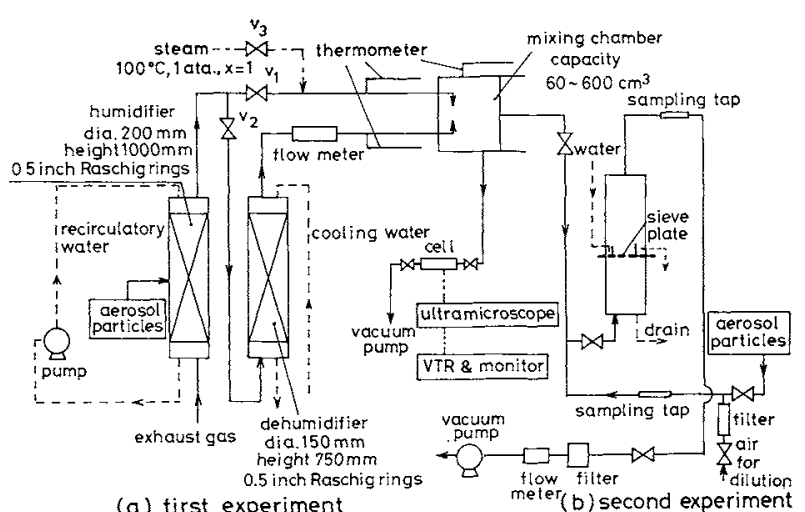

(a) tirst experiment

Fig. 11 Schematic diagram of experimental apparatus

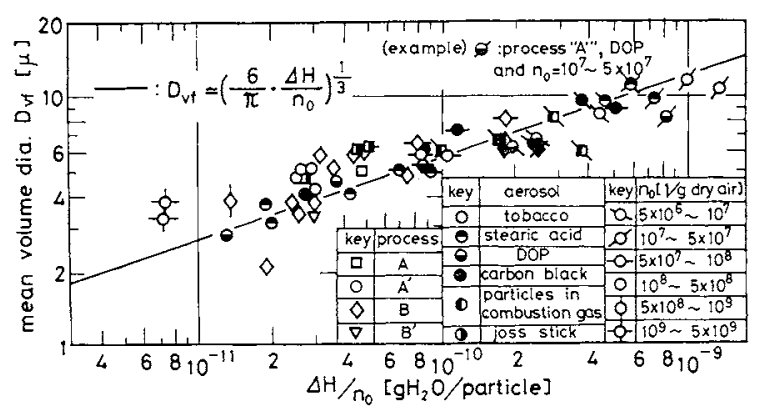

Fig. 12 Relation between grown particle diameter $D_{v f}$ and condensable water vapor per single particle

grown particles was the same as that appearing in the previous papers ${ }^{1,2}$. Experimental results obtained were plotted in the same graph as those of the previous paper ${ }^{2)}$, which is shown in Fig. 12. The results obtained in the previous work are also collectively plotted in the figure. It will be found that the size of grown particles in all processes "A", "A", " $B$ " and " $B$ "' can be evaluated by Eq. (5).

In the second experiment, a sieve-plate scrubber was used, and the schematic diagram is shown in Fig. 11(b). The dimensions and shape of the scrubber are shown in Fig. 13. The test aerosol used was a fog cloud of aqueous ammonium chloride solution, and the method of generation was the same as that used by Fujitani ${ }^{3}$. Upstream and downstream of the scrubber the aerosol was sampled under isokinetic sampling conditions. The measurement methods of particle number concentration and particle size distribution were the same as those used in the first experiment. Figure 14 (a) shows the experimental collection efficiency of sieve-plate scrubber against superficial velocity $u_{G}$, and Fig. 14 (b) compares particle size distribution before and after the sieve-plate scrubber. Aerosol particles without particle growth, namely the supplied aerosol particles themselves, are found to be very difficult to capture, as shown in Fig. 14(a). When the same particles were grown by condensation after 


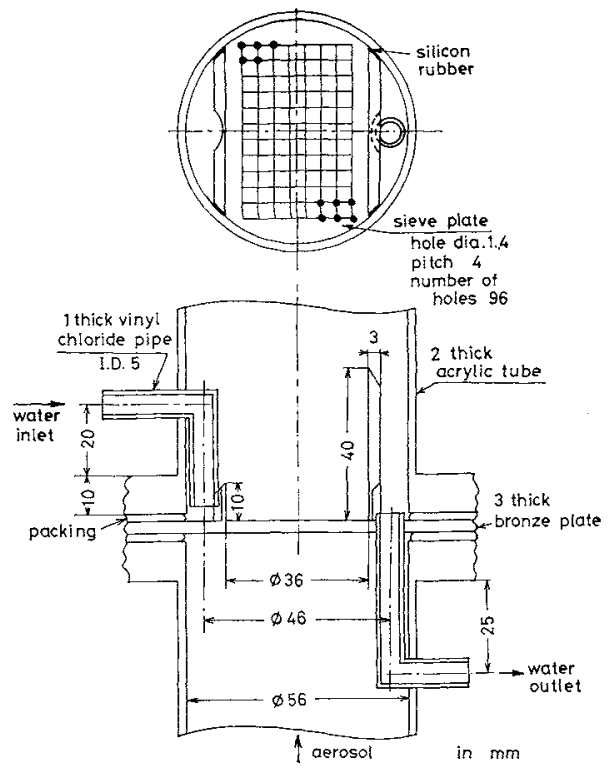

Fig. 13 Sieve-plate scrubber

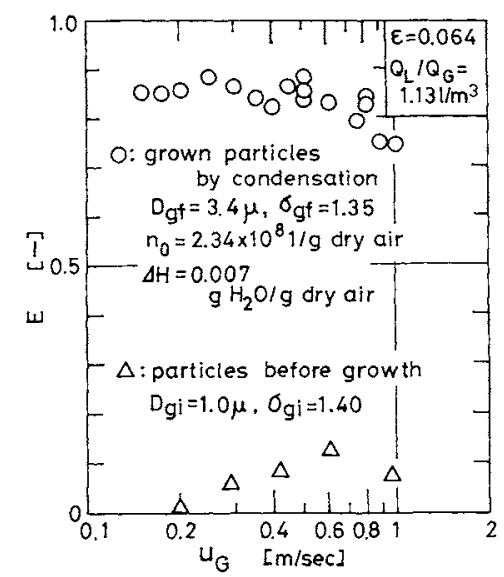

Fig. 14(a) Experimental collection efficiency of sieve plate scrubber

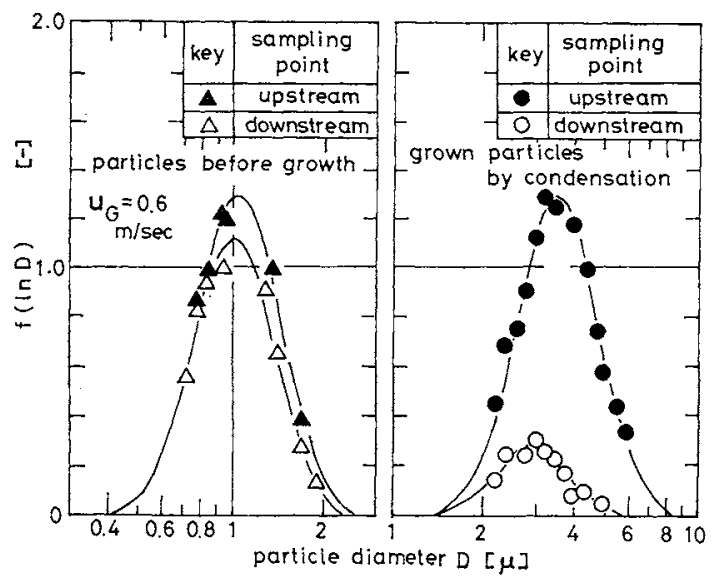

Fig. 14(b) Particle size distribution before and after growth

dilution, the collection efficiency of such particles is found to increase by $80 \sim 90 \%$. In this experiment, the particles were grown by the process " $\mathrm{A}$ "" and " $\mathrm{A}$ ". The mechanism of particle collection by a sieve-plate scrubber, which has not been clearly analyzed yet, is considered to be that caused by inertia, because the collection efficiency of particles increased with particle size. Under these experimental conditions, the pressure drop was less than $100 \mathrm{mmH}_{2} \mathrm{O}$. Improvement in particle collection efficiency due to condensation growth was also seen under other experimental conditions.

\section{Conclusion}

Application of the phenomena of particle growth by condensation to industrial dust collection was developed. Four typical processes were proposed for the effective application of the phenomena and the procedure of their utilization was shown according to various exhaust gas conditions. The technique for size enlargement of aerosol particles by condensation was found to be essentially applicable to any industrial exhaust gas which contains submicron dust particles in low number concentration when the appropriate process shown in the paper is selected. The results suggested that exhaust gas of high temperature and high humidity is especially profitable to apply this technique because no heat source other than cooling water is necessary. Exhaust gas of low temperature, such as $30^{\circ} \mathrm{C}$ or below, on the other hand, is advantageous in very simple apparatus but is disadvantageous in necessity of steam.

\section{Nomenclature}

$$
\begin{aligned}
& D, D_{g} \quad=\text { diameter and geometric mean diameter } \\
& D_{v i}, D_{v f}=\text { volume mean diameter before and after } \\
& \text { growth, respectively } \\
& E \quad \quad=\text { particle collection efficiency } \\
& H \quad=\text { absolute humidity } \quad\left[\mathrm{g} \mathrm{H}_{2} \mathrm{O} / \mathrm{g}\right. \text { dry air] } \\
& \Delta H \quad=\text { condensable water vapor } \quad\left[\mathrm{g} \mathrm{H}_{2} \mathrm{O} / \mathrm{g}\right. \text { dry air] } \\
& i \quad=\text { enthalpy } \quad \text { [cal/g dry air] [cal } / \mathrm{g} \text { steam] } \\
& n_{0} \quad=\text { particle number concentration [1/g dry air] } \\
& n(r, 0), n(r, \infty)=\text { particle number having particle radius } r \\
& \text { before and after growth [1/g dry air }] \\
& Q_{G}, Q_{L} \quad=\text { flow rate of gas and liquid } \quad\left[\mathrm{m}^{3} / \mathrm{min}\right][l / \mathrm{min}] \\
& Q_{s t} \quad=\text { quantity of steam injection } \quad[\mathrm{g} \mathrm{steam} / \mathrm{g} \text { dry air] } \\
& R_{h} \quad=\text { mixing ratio, g dry air of high temperature } \\
& \text { saturated air/g total dry air } \quad[-] \\
& r \quad=\text { radius of particle } \quad[\mathrm{cm}] \\
& \begin{array}{lll}
T & =\text { temperature } & {\left[{ }^{\circ} \mathrm{C}\right]}
\end{array} \\
& \begin{array}{lll}
u_{G} & =\text { superficial velocity }[\mathrm{m} / \mathrm{sec}]
\end{array} \\
& x \quad=\text { dryness fraction } \quad[-] \\
& \varepsilon \quad=\text { porosity of sieve plate } \quad[-] \\
& \rho_{s} \quad=\text { density of condensed liquid } \quad\left[\mathrm{g} / \mathrm{cm}^{3}\right] \\
& \sigma_{g} \quad=\text { geometric standard deviation } \quad[-] \\
& \begin{array}{ll}
e & =\text { equilibrium state of air } \\
f & =\text { final state shown in Fig. } 1 \\
g & =\text { initial state of air } \\
i & =\text { initial state } \\
s & =\text { saturated } \\
s f & =\text { saturated air in final state } \\
s h & =\text { high-temperature saturated air }
\end{array}
\end{aligned}
$$




$$
\begin{array}{ll}
\text { sl } & =\text { low-temperature saturated air } \\
\text { st } & =\text { steam } \\
w f & =\text { water in final state }
\end{array}
$$

$\langle$ Superscripts〉

$\quad=$ wet

$=$ dry

\section{Literature Cited}

1) Yoshida, T., Y. Kousaka and K. Okuyama: Ind. Eng. Chem. Fundam., 14, 47 (1975).

2) Yoshida, T., Y. Kousaka and K. Okuyama: ibid., 15, 37 (1976).

3) Fujitani, Y.: Bull. Chem. Soc. Japan, 30, 683 (1957).

\title{
ELECTROOSMOTIC DEWATERING OF SLUDGE UNDER CONDITION OF CONSTANT VOLTAGE
}

\author{
HIROSHI YUKAWA, Hiroshi YOSHIDA, \\ KaZUMASA KOBAYASHI AND MASARU HAKODA \\ Department of Chemical Engineering, Gunma University, \\ Kiryu 376
}

\begin{abstract}
Electroosmotic dewatering is very effective for sludge which is difficult to dewater by mechanical methods.

Its use under condition of constant voltage was investigated. The mechanism of electroosmotic dewatering for compressible sludge under condition of constant voltage was studied by using the model of electroosmotic flow through a compressible-particle packed bed. The rate of electroosmotic dewatering and the electric power consumption were theoretically analysed. Experiments were performed by using compressible sludges such as white clay and bentonite. The equations obtained theoretically were confirmed experimentally. The theoretical equations of electroosmotic dewatering proposed in this paper are useful for the design of practical electroosmotic dewatering equipment. A few characteristics of electroosmotic dewatering under condition of constant voltage are also shown.
\end{abstract}

\section{Introduction}

A number of studies ${ }^{1,3}$ have been reported for electroosmotic dewatering of sludge. However, studies have scarcely ever been made from the point of view of design of practical equipment. Accordingly, there is almost no development of practical electroosmotic dewatering equipment. Electroosmotic dewatering is caused by mass transfer in the electric double layer by the action of an electric field. Therefore, the electroosmotic dewatering mechanism is qualitatively different from that of mechanical dewatering. Electroosmotic dewatering may be effective for colloidal and gelatinous sludges which are difficult to dewater by mechanical methods.

In the previous papers ${ }^{4,5}$, the electroosmotic dewatering for compressible sludge under condition of constant electric current was theoretically analysed by using the model of electroosmotic flow through a compressible-particle packed bed. It was experimentally confirmed that the equations obtained theo-

Received February 24, 1978. Correspondence concerning this article should be addressed to H. Yoshida, Dept of Ind. Chem., Oyama Tech. College, Oyama 323. retically were appropriate for the design of electroosmotic dewatering equipment. And it has become clear that electroosmotic dewatering is particularly effective for a gelatinous sludge such as bentonite ${ }^{5}$.

Komagata $^{2}$ has proposed as electroosmotic dewatering equation for incompressible sludge by use of the straight capillary tubes model under condition of constant voltage. But this theoretical equation is not adequate for electroosmotic dewatering equipment for an actual compressible sludge because the straight capillary tubes model is not reasonable for compressible sludge.

The design equations of electroosmotic dewatering for compressible sludge under condition of constant voltage are presented in this paper. To obtain them, the rate of electroosmotic dewatering and the electric power consumption were theoretically analysed by using the model of electroosmotic flow through a compressible-particle packed bed. The reliability of these equations was ascertained experimentally by use of compressible sludges such as white clay sludge and gelatinous bentonite sludge. Then the experimental results were compared with the calculated ones by the 